\title{
Laser Cladding Composite coatings of Co60 and TiCN
}

\section{Xiaowen WANG ${ }^{1}$, Xiaojuan YANG $^{1}$, * Jianbin ZHANG ${ }^{1, \text { a }}$ and ${ }^{*}$ Dongmei $\mathrm{YU}^{2}{ }^{2, \mathrm{~b}}$}

\author{
${ }^{1}$ State Key Laboratory of Non-ferrous Metal Alloys and Processing of Ministry of Education, \\ Lanzhou University of Technology, Lanzhou, 730050, China \\ ${ }^{2}$ State Key Laboratory for Mechanical Behavior of Materials, Xi'an Jiaotong University, Xi'an, \\ 710049, China \\ aemail:jbzhangjb@hotmail.com (*Corresponding author), \\ bemail:bjyudongmei@gmail.com (*Corresponding author)
}

Keywords: Laser Cladding; Co60; TiCN; Microstructure; Corrosion

\begin{abstract}
An approach for fabricating specimens with composite coatings of Co60 and TiCN (titanium carbonitride) via selective laser cladding (SLD) is presented. The focus aims at adding (0\%wt., 10\%wt., 20\%wt., 30\%wt., 40\%wt., and 50\%wt.)TiCN at gradual mass fraction in Co60 powder as mixed cladding composite material. The laser cladding specimens are examined for microstructure, composition, microhardness and resistance to corrosion. Experimental results indicate that Co60+(30\%wt.)TiCN laser cladding layer has remarkable resistance to corrosion, attributing to dendrite microstructure, Co60 as binder phase and ceramic particles TiCN and its decomposition products as strengthening phase dispersed in the cladding layer.
\end{abstract}

\section{Introduction}

The cermet is a sintered mixture of metals and ceramics at high temperatures, in which ceramic particles are wrapped metal phase with ductility, so that it has not only ceramic high-strength, high hardness, corrosion resistance, high temperature and other excellent performance, but also has good toughness and plasticity of metal, playing a vital role in the tools and structural materials [1].

The composite coatings of self-fluxing alloy-coated carbides currently are applied to metal and alloy surface to improve their properties, attributed to good wettability of self-fluxing alloy binder phase, like $\mathrm{Fe}$, $\mathrm{Co}$ and $\mathrm{Ni}$ which are three kinds of the most common self-fluxing alloys in application, and strengthening of dispersed carbide particles, in which carbides, especially WC and TiC are commonly used.

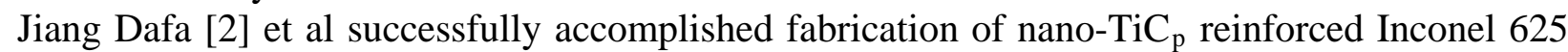
composite coatings by partial dissolution of micro-TiC $\mathrm{p}_{\mathrm{p}}$ through laser cladding energy input control, demonstrating that nano-particulate reinforced metal matrix composites (nPRMMCs) exhibit excellent comprehensive properties with the hardness and modulus of the nPRMMCs being 3.36 GPa and $190.91 \mathrm{GPa}$, increased by $10.33 \%$ and $12.39 \%$ respectively compared to laser cladded Inconel 625 substrate with the specific energy input of $25.3 \mathrm{~kJ} / \mathrm{g}$.

Raghuvir Singh [3] et al performed laser cladding of Stellite 6 on stainless steel 13Cr-4Ni to study the performance of clad on solid particle erosion (SPE) and cavitation erosion at varied energy densities (from 32 to $52 \mathrm{~J} / \mathrm{mm}^{2}$ ), as a result of Stellite 6 cladding showing significantly enhanced the solid particle erosion resistance of stainless steel and cavitation resistance.

TiCN, a continuous solid solution formed by $\mathrm{TiC}$ and $\mathrm{TiN}$, is a new candidate of coating material due to the excellent properties: high hardness, abrasion, corrosion and high temperature resistance [4]. TiCN combines high hardness of cemented carbide with high temperature properties of ceramic materials, which has drawn more and more attention in the industry application, such as metalworking and high temperature parts in automobile manufacturing and aerospace fields, as a consequence of a very broad application prospect [5]. The bonding strength between TiN coating and substrate is less than that between TiC coating and substrate. TiN coating easily peels off, whose hardness is low than that of TiC coating, and is ablated due to oxidization during cutting at high temperatures. TiC coating has high hardness and resistance to oxidation, but it is brittle and has 
bad resistance to impact. Combined with the features and advantages of $\mathrm{TiC}$ and $\mathrm{TiN}$, TiCN is potential transition between metals and ceramics.

Laser cladding advantages: (1) the appropriate laser parameters with high energy density and fast heating speed, have little thermal influence on the substrate, resulting in small deformation simultaneously without residual stress in the workpiece [6]; (2) the dilution of substrate can be limited at extremely low level (typically $2 \%$ to $8 \%$ ) by controlling the laser input energy, resulting in maintaining the excellent performance of original cladding materials; (3) metallurgical bonding between the laser cladding layer and the substrate ensures fastness and reliability [7]. Laser cladding significantly improves the resistance to corrosion, heat and oxidation of primary substrate surface to achieve surface modification or repair, not only meeting the specific performance of material surface, but also saving a mass of precious elements.

\section{Experimental}

\section{Materials}

Co60 and TiCN powder produced from Zhuzhou Defeng Powder Metallurgy Technology Co., Ltd, were used as cladding materials, whose compositions were given (refer with: Table 1). The surfaces of the substrate were sanded. Before laser cladding, the surfaces of substrate were grinded with abrasive paper of No.150 and cleaned with acetone. The basic physical properties of Co60 and TiCN powder are as follows. For Co-based alloy powder, grain size: -128 to 280; bulk density: 4.71 g/ $\mathrm{cm}^{3}$; mobility: 16s/50g; hardness: 380 410HV. For TiCN powder, relative atomic mass: 74; hardness: $3300 \mathrm{HV}$, friction coefficient: $0.21 \mathrm{vs} \mathrm{Ni}$.

Table 1. Compositions of Co60 and TiCN powders

\begin{tabular}{|c|c|c|c|c|c|c|c|c|c|c|c|c|c|c|c|c|c|c|}
\hline $\begin{array}{l}\text { Element } \\
\text { s/ wt.\% }\end{array}$ & TiCN & Co & $\mathrm{Cr}$ & C & $\mathrm{Ni}$ & W & $\mathrm{Mn}$ & $\mathrm{N}$ & $\mathrm{Ti}$ & $\mathrm{O}$ & $\mathrm{Fe}$ & $\mathrm{P}$ & Mo & $\mathrm{Na}$ & K & $\mathrm{S}$ & $\mathrm{Ca}$ & Si \\
\hline Co60 & - & $\begin{array}{l}\mathrm{Re} \\
\text { mai } \\
\mathrm{n}\end{array}$ & $\begin{array}{l}28.0 \\
\sim 32 . \\
0 \\
\end{array}$ & $\begin{array}{l}1.0 \sim \\
1.2\end{array}$ & $\begin{array}{l}2.0 \sim \\
3.0\end{array}$ & $\begin{array}{l}4.0 \sim \\
6.0\end{array}$ & $\begin{array}{l}0.4 \sim \\
0.8\end{array}$ & - & - & - & $\leq 3$ & - & & & & & & $\begin{array}{l}1.0 \\
\sim 2 . \\
0\end{array}$ \\
\hline \multirow[b]{2}{*}{ TiCN } & \multirow[b]{2}{*}{$\begin{array}{l}\text { Remai } \\
\mathrm{n}\end{array}$} & \multirow[b]{2}{*}{-} & \multirow[b]{2}{*}{-} & \multirow[b]{2}{*}{9.92} & \multirow[b]{2}{*}{ - } & \multirow[b]{2}{*}{ - } & \multirow[b]{2}{*}{ - } & \multirow[b]{2}{*}{$\begin{array}{l}10 . \\
89\end{array}$} & \multirow[b]{2}{*}{$\begin{array}{l}78 . \\
27\end{array}$} & \multirow[b]{2}{*}{0.38} & \multirow[b]{2}{*}{$\begin{array}{l}0.0 \\
51\end{array}$} & \multicolumn{7}{|l|}{ 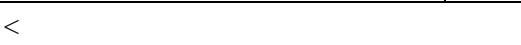 } \\
\hline & & & & & & & & & & & & $\begin{array}{l}0.0 \\
06\end{array}$ & $\begin{array}{l}0.00 \\
6\end{array}$ & $\begin{array}{l}0.0 \\
05\end{array}$ & $\begin{array}{l}0.0 \\
05\end{array}$ & $\begin{array}{l}0.0 \\
04\end{array}$ & $\begin{array}{l}0.0 \\
05\end{array}$ & $\begin{array}{l}0.00 \\
6\end{array}$ \\
\hline
\end{tabular}

The microstructure of Co60 powder is spherical, grain size is similar and distributes evenly. While TiCN powder is a different appearance, grains with different sizes are irregular, and distribute unevenly (refer with: Fig. 1).

The laser cladding system provided with $10 \mathrm{KW} \mathrm{\textrm {CO } _ { 2 }}$ laser beam, by which preset Co60 and TiCN powders. The conditions of single pass clad layer prepared were laser power of $4 \mathrm{KW}$, scanning distance of $40 \mathrm{~mm}$, beam size of $2 \mathrm{~mm}$ in diameter on the top of the substrate, travelling speed of $7 \mathrm{~mm} / \mathrm{s}$, shielding gas (argon) flowrate of $20 \mathrm{~L} \cdot \mathrm{min}-1$, and room temperature of $26^{\circ} \mathrm{C}$.

The laser cladded specimens were cut transversely, polished and etched with a mixture of $30 \mathrm{~mL}$ of $\mathrm{HCl}$ and $10 \mathrm{~mL} \mathrm{HNO}_{3}$. The microstructures were observed with an MFe3 optical microscope (OM) and a Quanta FEG450 scanning electron microscope (SEM). The phases of the cladding layer were analyzed by D/Max-2400 X-ray diffractometer with Cu K radiation. A step of $0.02^{\circ}$ was used to scan $2 \theta$ from $20^{\circ}$ to $110^{\circ}$. The microhardness of layer was tested by HV-1000 microhardness instrument. 


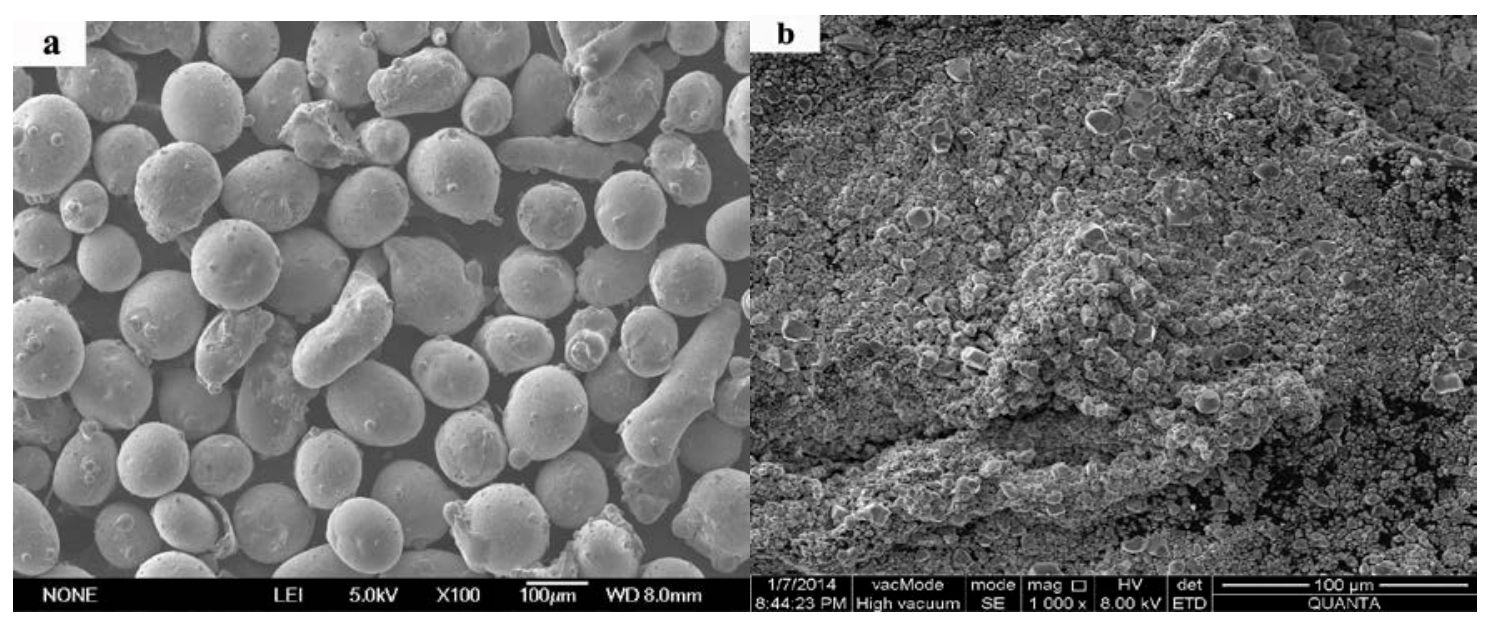

(a) Microstructure of Co60 powders; (b) Microstructure of TiCN powders

Fig. 1. Experimental details

\section{Results and discussion}

\section{Microstructure}

The microstructures of cladding layer powder mixture of Co60 and TiCN on the substrate were shown (refer with: Fig. 2), in which Co60, 10\%TiCN, 20\%TiCN, 30\%TiCN, 40\%TiCN and $50 \% \mathrm{TiCN}$ represent the cladded powder compositions of Co-based alloy powder, $\mathrm{Co}+(10 \%$ wt.)TiCN, $\quad \mathrm{Co}+(20 \%$ wt. $) \mathrm{TiCN}, \quad \mathrm{Co}+(30 \% \mathrm{wt}.) \mathrm{TiCN}, \quad \mathrm{Co}+(40 \% \mathrm{wt}.) \mathrm{TiCN}, \quad$ and $\mathrm{Co}+(50 \% \mathrm{wt}$.) TiCN mixed powder, respectively.
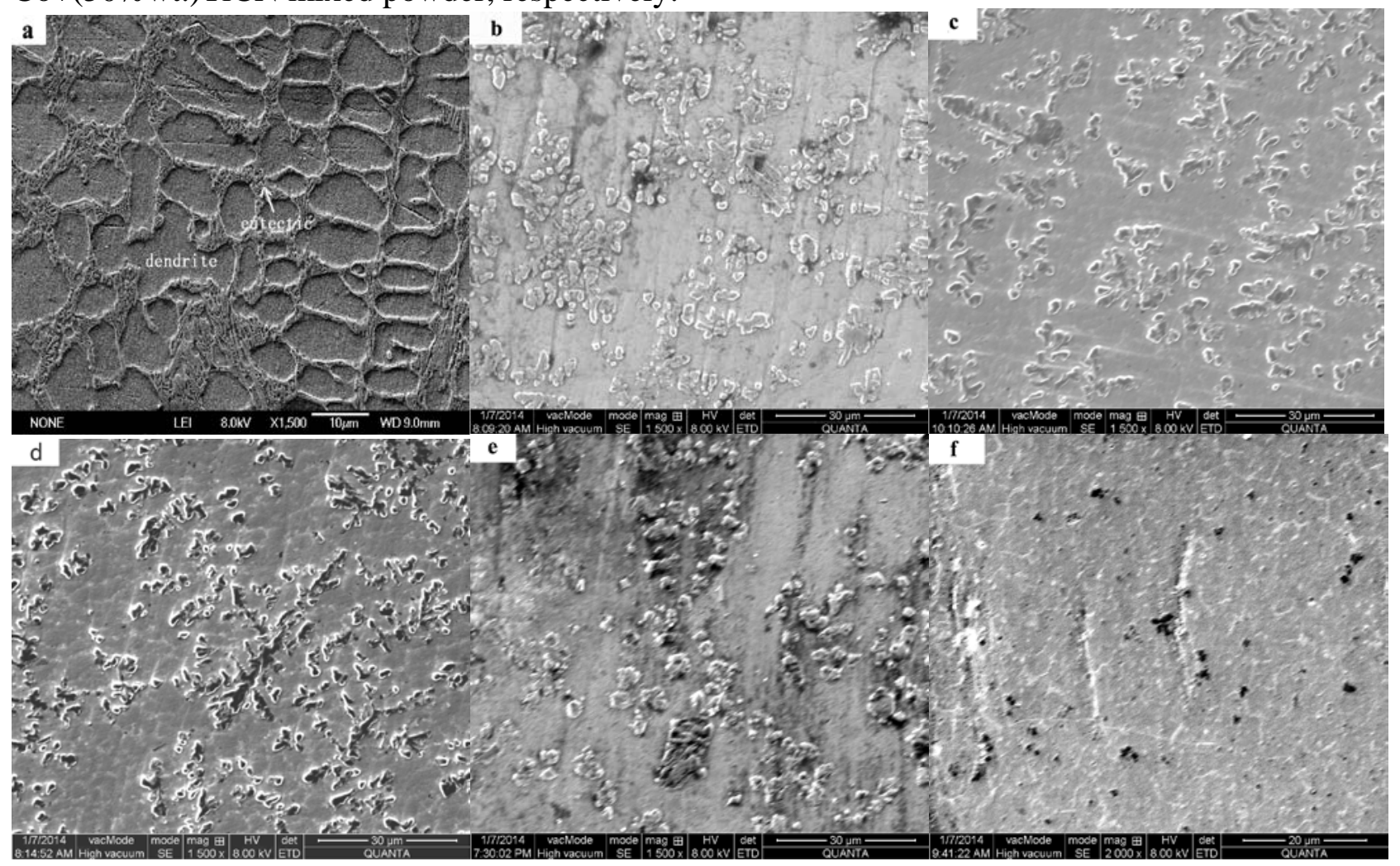

Fig. 2. Microstructure of Co60/TiCN laser cladding layers: (a) Co60; (b) 10\% wt. TiCN; (c) 20\% wt. TiCN; (d) 30\% wt. TiCN; (e) 40\% wt. TiCN; (f) 50\% wt. TiCN

The composition ratios of alloy powder (Co60+(0\%wt., 10\%wt., 20\%wt., 30\%wt., 40\%wt., and $50 \%$ wt.)TiCN) in cladding composite material appear to be gradient. Experimental results show that the content of TiCN has a significant effect on the organization of coatings. The organization of coating distributes unevenly and is coarse without adding TiCN powder; while the organization evenly disperses with adding, which suggest that TiCN powder is helpful to grain dispersion of cladding composite material. In addition, the solidification rate of cladding layer and the 
concentration of TiCN in molten pool have some influence on the morphology of TiCN secondary phase due to the laser beam with rapid heating and cooling. When the content of TiCN is less (0\%wt., 10\%wt., and 20\%wt.), TiCN completely dissolves in the eutectic organization without the precipitated TiCN secondary phase, and the microstructure consists of primary dendrite (Co solid solution phase) and the interdendritic eutectic $\left(\mathrm{M}_{23} \mathrm{C}_{6}, \mathrm{M}_{7} \mathrm{C}_{3}\right)$ composition; with the increase in TiCN content (30\%wt., 40\%wt., and 50\%wt.), the fusion-precipitation mechanism of TiCN in cladding layer dominates, and the precipitated TiCN appears in organization.

\section{XRD}

The cladding materials in this experiment are Co60 and ceramic particles of TiCN. Co60 is binder phase and ceramic particles of TiCN is primary hard enhanced phase in the cladding region, where TiCN is decomposed into $\mathrm{TiC}$ and $\mathrm{TiN}$ by the heat source of laser beam, which are dispersed in the binder phase to play a strengthening role. XRD patterns of Co60/TiCN laser cladding composite material are shown (refer with: Fig.3), in which Co60, 20TiCN, 30TiCN, 40TiCN and 50TiCN respectively represent the cladded powder compositions of Co-based alloy powder, $\mathrm{Co}+(20 \%$ wt. $) \mathrm{TiCN}, \mathrm{Co}+(30 \%$ wt. $) \mathrm{TiCN}, \mathrm{Co}+(40 \%$ wt. $) \mathrm{TiCN}, \mathrm{Co}+(50 \%$ wt. $) \mathrm{TiCN}$, while unlike Co60, TiCN is not the cladded TiCN, but the original TiCN powder as a comparison.

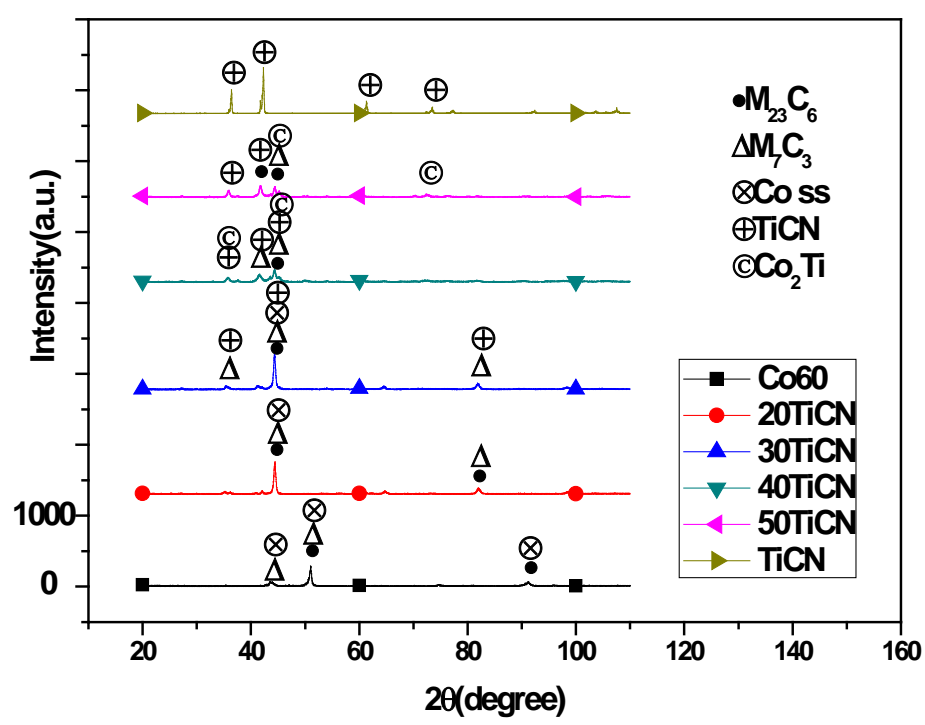

Fig. 3. XRD patterns of Co60/(0\%wt., 10\%wt., 20\%wt., 30\%wt., 40\%wt., and 50\%wt.)TiCN laser cladding layers and TiCN powder

According to XRD pattern analysis, the main element composition in Co60 and Co60 + 20\%wt. TiCN cladding regions are Co ss (solid solution), $\mathrm{M}_{23} \mathrm{C}_{6}$, and $\mathrm{M}_{7} \mathrm{C}_{3}$, where Co ss represents Co solid solution, $\mathrm{M}$ represents $\mathrm{Cr}, \mathrm{Mn}$ or $\mathrm{Fe}$, and the symbols possess the same meanings below; the main element composition in Co60 $+30 \%$ wt. TiCN cladding region are Co ss, $\mathrm{M}_{23} \mathrm{C}_{6}, \mathrm{M}_{7} \mathrm{C}_{3}$, and TiCN; and the main element composition in Co60 + 40\%wt. TiCN and Co60 + 50\%wt. TiCN cladding regions are $\mathrm{M}_{23} \mathrm{C}_{6}, \mathrm{M}_{7} \mathrm{C}_{3}$, TiCN and $\mathrm{Co}_{2} \mathrm{Ti}$.

\section{Microhardness}

Microhardness of Co60/TiCN laser cladding composite material has been greatly improved in comparison with that of substrate 40CrNiMo shown (refer with: Fig. 4); and the content of TiCN has a significant effect on the average hardness of the cladding composite material. When the content of TiCN reaches 30\%wt., the average hardness of cladding layer is a maximum of $1027 \mathrm{HV}_{0.2}$, which increases by about $560 \%$ compared with the average hardness of the substrate $\left(183.3 \mathrm{HV}_{0.2}\right)$. 


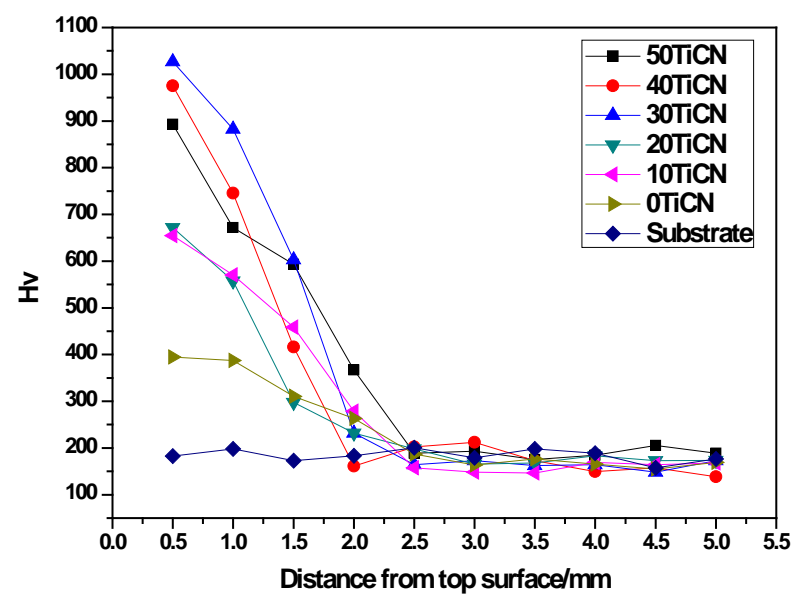

Fig. 4. Microhardness of Co60/ (0\%wt., 10\%wt., 20\%wt., 30\%wt., 40\%wt., and 50\%wt.)TiCN laser cladding layers

TiCN particles at high temperatures during laser cladding dissolve and react with the surrounding alloys, and the formation of dispersed hard phases appears in the subsequent rapid solidification, such as $\mathrm{M}_{23} \mathrm{C}_{6}, \mathrm{M}_{7} \mathrm{C}_{3}$ and TiCN. Initially, the more content of TiCN is added, the more obvious is dispersion strengthening. Therefore, the closer is the distance from the surface of the cladding layer, the higher is the hardness.

\section{Resistance to corrosion}

Corrosion rate of the specimens are calculated according to weight variation of specimens tested before and after $8 \mathrm{~h}$ neutral salt spray corrosion, in order to directly assess the corrosion resistance of Co60/TiCN laser cladding layers.

Salt spray corrosion rate of specimens is calculated (refer with: Eq. 1) [8]

$V=\frac{\mathrm{W}_{0}-W_{1}}{S \times t}$

Where $\mathrm{V}$ is corrosion rate $\left(\mathrm{g} / \mathrm{m}^{2} \cdot \mathrm{h}\right), \mathrm{W}_{0}$ and $\mathrm{W}_{1}$ are respectively the specimen weight before and after corrosion test (g), $\mathrm{S}$ is the exposed surface area of specimens $\left(\mathrm{m}^{2}\right)$, and $\mathrm{t}$ is the corrosion time (h).

The corrosion rate of Co60/TiCN laser cladding layers is as follows: $30 \% w t$. (TiCN) $<20 \%$ wt. (TiCN) $<50 \%$ wt. (TiCN) $<10 \%$ wt. (TiCN) $<40 \%$ wt. (TiCN) $<0 \%$ wt. (TiCN) $<$ Substrate (40CrNiMo). 0\%wt.TiCN represents the cladding layer with pure Co-based alloy powder. The corrosion resistance of Co60/TiCN laser cladding layers are obviously superior to substrate, resulting from precipitation strengthening of TiCN ceramic particles and its decomposition products with good corrosion resistance. The laser cladding treatment significantly improves the corrosion resistance of substrate, ceramic particles play a remarkable role in coating and the content of TiCN has different effect on corrosion resistance. The corrosion rate of Co60+30\%wt.TiCN laser cladding layer is the lowest among them, indicating that this coating has the excellent corrosion resistance.

\section{Conclusions}

The major conclusions of Co60/TiCN laser cladding layers with different TiCN contents are as follows:

(1) When the content of TiCN is less (0\%wt., 10\%wt., and 20\%wt.), TiCN completely dissolves in the eutectic organization without the precipitated TiCN secondary phase, and the microstructure consists of primary dendrite (Co solid solution phase) and the interdendritic eutectic $\left(\mathrm{M}_{23} \mathrm{C}_{6}, \mathrm{M}_{7} \mathrm{C}_{3}\right.$ ) composition; with the increase in the content (30\%wt., 40\%wt., and 50\%wt.) of TiCN, the fusion-precipitation mechanism of TiCN in cladding layer dominates, and the precipitated TiCN appears in organization. 
(2) The content of TiCN in Co60/TiCN composite cladding composite material has a significant effect on the average microhardness. When the content of TiCN reaches 30\%wt., the average microhardness of composite material reaches a maximum of $1027 \mathrm{HV}_{0.2}$, and increases by about $560 \%$ in comparison with that of the matrix $\left(183.3 \mathrm{HV}_{0.2}\right)$.

(3) Corrosion rate of the specimens indicates laser cladding layers obviously improve the corrosion resistance of substrate, due to TiCN ceramic particles and its decomposition products with good corrosion resistance. Results indicate that Co60/ (30\%wt.)TiCN laser cladding layer has the excellent corrosion resistance.

\section{References}

[1] Li Rongjiu. Ceramic-metal composite material [M]. Beijing: Metallurgical Industry Press, 2004:1.

[2] Dafa Jiang, ChenHong, Minlin Zhong. Fabrication of nano-TiCp reinforced Inconel 625 composite coatings by partial dissolution of micro-TiCp through laser cladding energy input control [J]. Surface \& Coatings Technology, 2014, 249:125-131.

[3] Raghuvir Singh, Damodar Kumar, S.K. Mishra, et al. Laser cladding of Stellite 6 on stainless steel to enhance solid particle erosion and cavitation resistance [J]. Surface \& Coatings Technology, 2014, 25: 87-97.

[4] Monteverde F, Medri V, and Bellosi A. Microstructure of hot-pressed TiCN-based cermets [J]. Eur Ceram Soc., 2002, 22: 2587-2593.

[5] TANG Dapei, GAO Qing, and JIANG Xiaoyu. Structure and Property and Bonding Strength of Titanium Carbonitride Coating [J]. Surface Technology, 2004, 33(4): 13-15.

[6] G. Telasang, J.DuttaMajumdar, G.Padmanabham, et al. Effect of laser parameters on microstructure and hardness of laser clad and tempered AISI H13 tool steel [J]. Surface \& Coatings Technology, 2014, 7: 1-11

[7] Song Liping. LASER SURFACE MODIFICATION AND APPLICATION [J]. Physics and Engineering, 2010, 20(4): 42-44.

[8] Chinese Society for Corrosion and Protection. Corrosion test methods and corrosion detection technology [M]. Beijing: Chemical Industry Press, 1996. 